\title{
Probability assessment of mechanical trimming using hot half-trimming in hot stamping process
}

\author{
Jun-Ho Shin ${ }^{1}$, Kyung-Hun Lee ${ }^{2}$, Byung-Min Kim ${ }^{3}$, and Dae-Cheol Ko ${ }^{1,3, a}$ \\ ${ }^{1}$ Graduate School of Convergence Science, Pusan National University, South Korea \\ ${ }^{2}$ PNU-IFAM Joint Research Center, Pusan National University, South Korea \\ ${ }^{3}$ School of Mechanical Engineering, Pusan National University, South Korea
}

\begin{abstract}
The objective of this study is to investigate the probability of mechanical trimming using hot half-trimming in actual hot stamping process. Hot half-trimmed part can be inaccurately positioned on mechanical trimming die by relatively low accuracy of automatic transferring system or manual way, leading to the change of clearance in mechanical trimming. Taking into account this position error, a suitable operation window for trimming of flat and inclined part was constructed by FE-simulation and then was verified by experiment. It was determined from the operation window that effective mechanical trimming for both flat and inclined part can be performed successfully with hot half-trimming depth of $1.0 \mathrm{~mm}$ in hot half-trimming and clearance between $0.1 \mathrm{~mm}$ and $0.124 \mathrm{~mm}$ in subsequent mechanical trimming, without regard to position error.
\end{abstract}

\section{Introduction}

For the demand of lightweight construction and the improvement of crash safety in automobiles, the hot stamping process of quenchable boron alloyed steel sheets is widely used to manufacturing of automotive parts. After hot stamping, hot stamped part requires subsequent cutting processes such as trimming, blanking and punching, to remove excess or unnecessary material from the parts. However, most of manufacturers in automotive industries are encountering difficulties in cutting of hot stamped part due to its extremely high strength. Laser cutting technology is still used as an alternative process of mechanical trimming for hot stamped parts in actual industrial fields, which requires long production time in mass manufacturing, resulting in the increase of cost expenses. Therefore, it is inevitably required to develop an effective trimming technology for mass production of hot stamped parts [1-4].

The objective of this study is to investigate the probability of mechanical trimming using hot halftrimming in actual hot stamping process, which was suggested in previous study [4]. For complete cutting of the half-trimmed part, the part which is simultaneously performed with hot stamping is transferred to mechanical trimming die by automatic transferring system or manual way. During this process, hot half-trimmed part is inaccurately positioned on mechanical trimming die, which leads to the

\footnotetext{
${ }^{\text {a }}$ Corresponding author: dcko@pusan.ac.kr
}

This is an Open Access article distributed under the terms of the Creative Commons Attribution License 4.0, which permits unrestricted use, distribution, and reproduction in any medium, provided the original work is properly cited. 


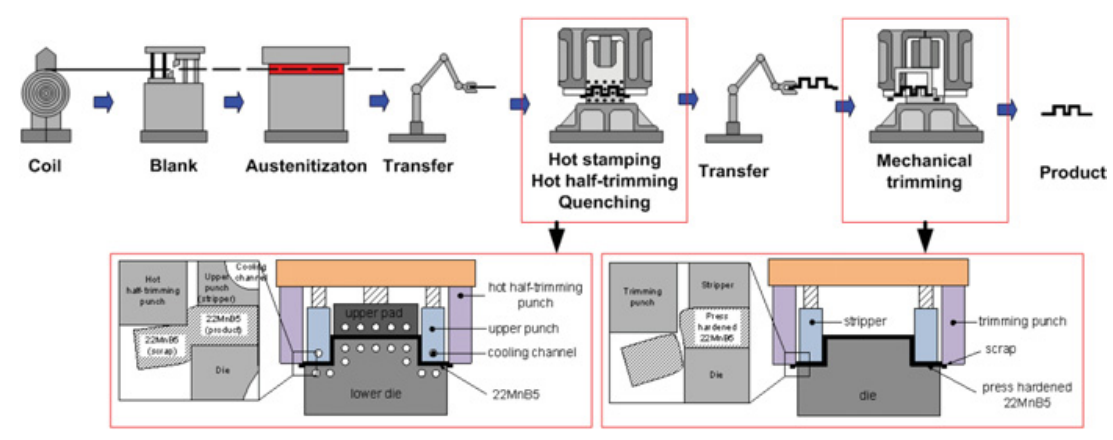

Figure 1. Schematic illustration of hot half-trimming and subsequent mechanical trimming [4].

change of clearance in mechanical trimming. Mechanical trimming of inclined part is often encountered for some product shape. Therefore, probability and robustness of mechanical trimming using hot-half trimming on position error in the trimming of flat and inclined part are investigated by FE-analysis and the results are verifed by experiment. As a result, a robust design is suggested with regard to hot half-trimming depth and clearance in subsequent mechnical trimming.

\section{Mechanical trimming using hot half-trimming}

\subsection{Brief description of the process}

A new mechanical trimming process using hot half-trimming has been suggested by previous study [4], as shown in Fig. 1. Near the end stage of hot stamping, sheet thickness on the desired trim line is reduced by hot half-trimming. After the hot half-trimmed part is transferred to the subsequent mechanical trimming die by automatic transferring system or worker, the part is fully trimmed by subsequent mechanical trimming. Pre-deformation of the sheet on the trim line before mechanical trimming can decrease the damage of trimming tool.

\subsection{Main process variables of the process}

Trimming experiment was carried out to investigate the effect of two main process variables on this process, such as hot half-trimming depth, $\mathrm{D}_{\mathrm{h}}$ in hot half-trimming and clearance, $\mathrm{C}$ in subsequent mechanical trimming. 22MnB5 sheet with thickness of $1.6 \mathrm{~mm}$ was cut to be $100 \mathrm{~mm} \times 50 \mathrm{~mm}$ in the initial length and width. The sheet was heated to $950^{\circ} \mathrm{C}$ in an electronic furnace for approximately 5 minutes and transferred to stamping die for hot half-trimming. Hot half-trimming was done at the temperature of approximately $750^{\circ} \mathrm{C}$, where the length of scrap was assumed to be $25 \mathrm{~mm}$, and then the hot half-trimmed specimen was quenched to achieve martensitic transformation. Finally, the specimen was fully trimmed by subsequent mechanical trimming process at room temperature.

Figure 2 shows SEM images of cross-sections of hot half-trimmed part with hot half-trimming depth, $\mathrm{D}_{\mathrm{h}}=1.0$ (Fig. 2(a)) and subsequent mechanically trimmed part with clearance, $\mathrm{C}=0.1 \mathrm{~mm}$ and $0.2 \mathrm{~mm}$ (Figs. 2(b) and 2(c). It was observed that traces of the roll-over and burnish features formed by previous hot half-trimming remained during subsequent mechanical trimming. Owing to deformation concentration around the corner edge deformed previously by the hot half-trimming punch and die (A and B in Fig. 2(a)), scrap was fully trimmed by very small punch penetration without further formation of burnish. It was found in Figs. 2(b) and 2(c) that variation of clearances in subsequent mechanical trimming can influence burr formation of trimmed edge. This result indicates that hot 


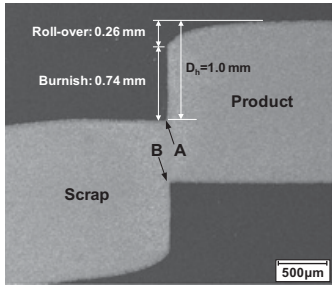

(a)

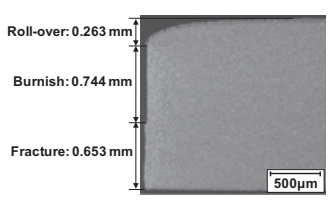

(b)

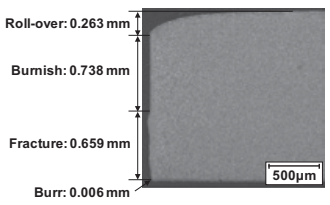

(c)

Figure 2. Cross-sections of (a) hot half-trimmed part with $\mathrm{D}_{\mathrm{h}}=1.0 \mathrm{~mm}$ and subsequent mechanically trimmed part with (b) $\mathrm{C}=0.1 \mathrm{~mm}$ and (c) $\mathrm{C}=0.2 \mathrm{~mm} \mathrm{[4].}$

Table 1. Process conditions for FE-simulation [4].

\begin{tabular}{ccccc}
\hline Process & Material & Flow stress & $\begin{array}{c}\text { Friction } \\
\text { factor }(\mathrm{m})\end{array}$ & Punch velocity (mm/s) \\
\hline $\begin{array}{c}\text { Hot-half } \\
\text { trimming }\end{array}$ & $22 \mathrm{MnB5}$ & J-MatPro & 0.3 & $V=\frac{2 \pi N}{60} h \sqrt{\frac{S}{h}-1}$ \\
\hline $\begin{array}{c}\text { Mechanical } \\
\text { trimming }\end{array}$ & $\begin{array}{c}\text { Quenched } \\
\text { 22MnB5 }\end{array}$ & $\bar{\sigma}=2250 \cdot \bar{\varepsilon}^{0.05}[\mathrm{MPa}]$ & 0.1 & $\begin{array}{c}\mathrm{N}: 25(\mathrm{rpm}) \\
\mathrm{H}: \mathrm{punch} \text { stroke }(\mathrm{mm}) \\
\mathrm{S}: \begin{array}{c}\text { crack diameter } \\
(\mathrm{mm})\end{array}\end{array}$ \\
\hline
\end{tabular}

half-trimming depth in hot half-trimming and clearance in subsequent mechanical trimming can directly influence the quality of the trimmed surface.

\section{Probability assessment of this process for real hot stamping}

\subsection{Suitable operation window}

FE-simulation was performed to obtain a suitable operation window of this process. The simulation was performed using commercial software, DEFORM under plane strain mode. The sheet with the thickness of $1.66 \mathrm{~mm}$ considering Al-Si coated layer was set as a plastic material and the tool was modeled as a rigid body. Process conditions in the FE-simulation of trimming process are listed in Table 1. The flow stress of 22MnB5 at elevated temperature for the FE-simulation of hot half-trimming was obtained from J-MatPro, whereas flow stress of press hardened 22MnB5 used in the FE-simulation of subsequent mechanical trimming was obtained from the tensile test.

To obtain a suitable operation window for real hot stamping, the effect of position error on the trimmed edge in mechanical trimming using hot-half trimming was investigated by FE-simulation, as shown in Fig. 3. Mechanical trimming with inclined angle was also considered in this study, because mechanical trimming of inclined part was often encountered for some product shape. In FE-simulation, mechanical trimming of flat part and inclined part with $\theta=-10^{\circ}$ and $+10^{\circ}$ was investigated for three cases of clearances in subsequent mechanical trimming, such as $\mathrm{C}=0.1 \mathrm{~mm}, 0.2 \mathrm{~mm}$ and $0.3 \mathrm{~mm}$, using hot half-trimming depth, $\mathrm{D}_{\mathrm{h}}=1.0 \mathrm{~mm}$. Position error was applied to all cases of FE-simulation, where position error of $0 \%$ indicates a normal trimming, contacting hot half-trimmed part with side face of die and position error of $100 \%$ indicates an abnormal trimming, contacting hot half-trimmed part with side face of punch.

Figure 4(a) shows a suitable operation window for trimming of flat part, where allowable height of burr and side protrusion in trimmed edge were assumed to be $50 \mu \mathrm{m}$. Successful trimmings were possible for all cases of clearances under $D_{h}=1.0 \mathrm{~mm}$, when position error was $0 \%$, i.e. hot half-trimmed 

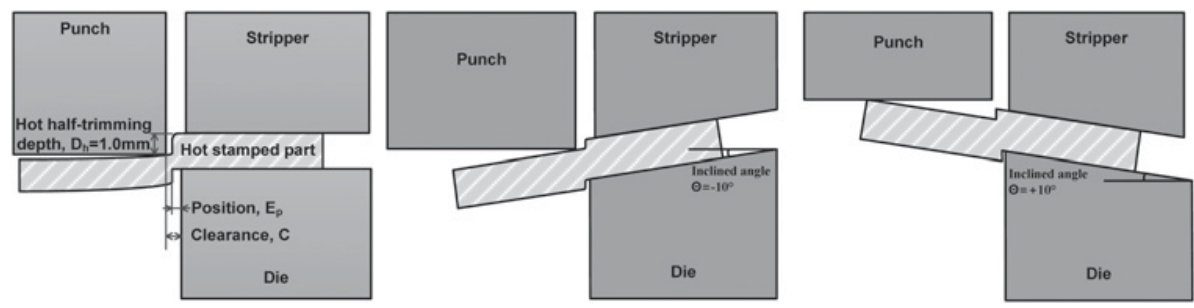

Figure 3. Process variables and position error in subsequent mechanical trimming after hot half-trimming.

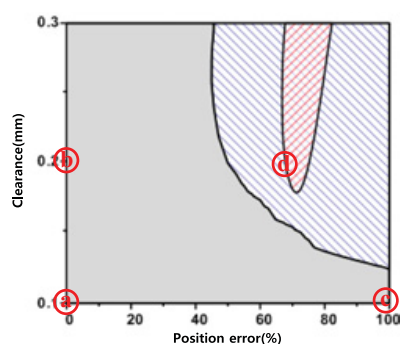

(a)

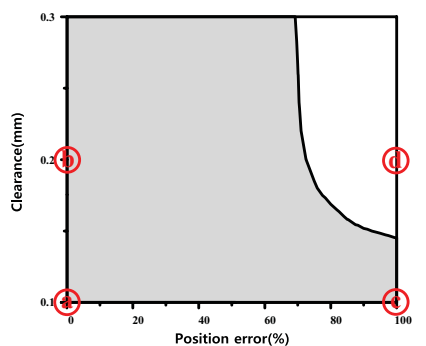

(b)

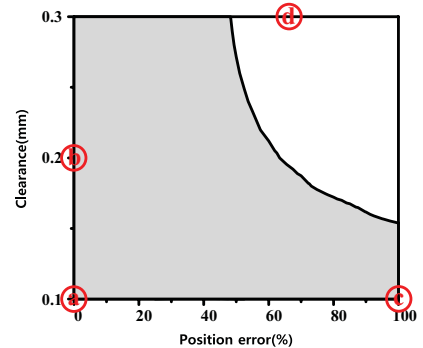

(c)

Figure 4. Operation window for mechanical trimming of (a) flat part and inclined part with (b) $\theta=-10^{\circ}$ and (c) $\theta=+10^{\circ}$ using $\mathrm{D}_{\mathrm{h}}=1.0 \mathrm{~mm}$.

part was accurately transferred to mechanical trimming die. When clearance in subsequent mechanical trimming was larger than $0.124 \mathrm{~mm}$, position error can result in the occurrence of large height of burr and side protrusion. Therefore, even though position error existed, successful trimmings can be performed with clearance between $0.1 \mathrm{~mm}$ and $0.124 \mathrm{~mm}$ in subsequent mechanical trimming.

Figures 4(b) and 4(c) show suitable operation windows for trimming of inclined part, where inclined angle of the part was considered as $\theta=-10^{\circ}$ and $+10^{\circ}$ under $D_{h}=1.0 \mathrm{~mm}$. Allowable burr height in trimmed edge was assumed to be $50 \mu \mathrm{m}$. Similar to trimming of flat part, successful trimmings were possible for all cases of clearances when position error was $0 \%$. When clearances in subsequent mechanical trimming were larger than $0.145 \mathrm{~mm}$ for $\theta=-10^{\circ}$ and $0.154 \mathrm{~mm}$ for $\theta=+10^{\circ}$, position error can result in the occurrence of large height of burr. Therefore, even though position error existed, the process can be performed with clearance between $0.1 \mathrm{~mm}$ and $0.145 \mathrm{~mm}$ for $\theta=-10^{\circ}$ and between $0.1 \mathrm{~mm}$ and $0.154 \mathrm{~mm}$ for $\theta=+10^{\circ}$ in subsequent mechanical trimming. It was determined in Fig. 4 that effective mechanical trimming using hot half-trimming for both trimming of flat and inclined part was possible with $\mathrm{D}_{\mathrm{h}}=1.0 \mathrm{~mm}$ in hot half-trimming and clearance between $0.1 \mathrm{~mm}$ and $0.124 \mathrm{~mm}$ in subsequent mechanical trimming without regard to position error.

\subsection{Experimental verification}

To verify the effectiveness of suitable operation windows, hot half-trimming and subsequent mechanical trimming by mechanical press of $400 \mathrm{kN}$ capacity, as mentioned in Sect. 2.2, were tested with the designed tool set under the same condition as FE-simulation.

Experimental results for trimming of flat part are shown in Fig. 5. Effective mechanical trimming can be performed at clearance of $0.1 \mathrm{~mm}$ without regard to position error (Figs. 5(a), 5(c)), where the trimmed edge showed very small height of burr for increase in clearance. But in case that $\mathrm{C}=0.2 \mathrm{~mm}$, position error of $66 \%$ resulted in relatively large height of burr and side protrusion (Figs. 5(b), 5(d)). 


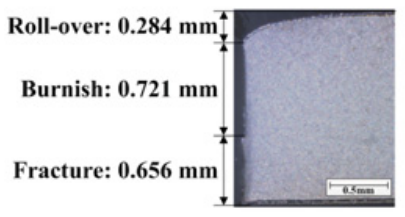

(a)

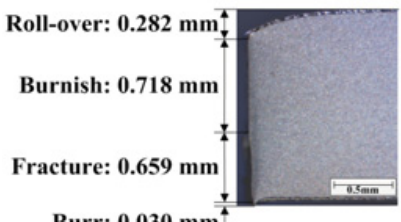

Burr: $0.030 \mathrm{~mm}$

(c)

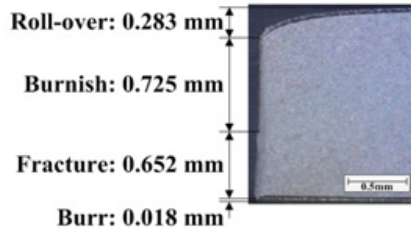

(b)

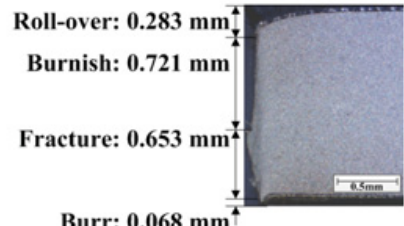

(d)

Figure 5. Verification of operation window shown in Fig. 4(a); (a) $\mathrm{C}=0.1 \mathrm{~mm}$ with $\mathrm{E}_{\mathrm{p}}=0 \%$, (b) $\mathrm{C}=0.2 \mathrm{~mm}$ with $\mathrm{E}_{\mathrm{p}}=0 \%$, (c) $\mathrm{C}=0.1 \mathrm{~mm}$ with $\mathrm{E}_{\mathrm{p}}=100 \%$ and (d) $\mathrm{C}=0.2 \mathrm{~mm}$ with $\mathrm{E}_{\mathrm{p}}=66 \%$ using $\mathrm{D}_{\mathrm{h}}=1.0 \mathrm{~mm}$.

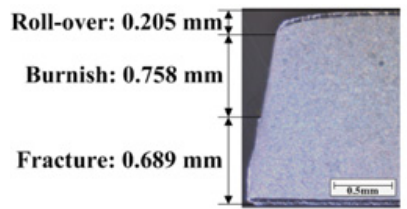

(a)

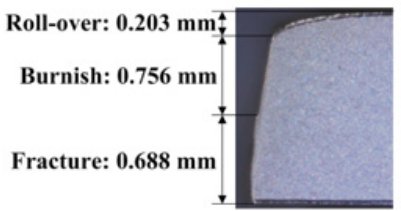

(c)

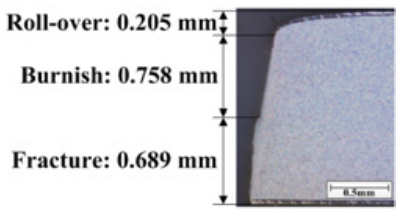

(b)

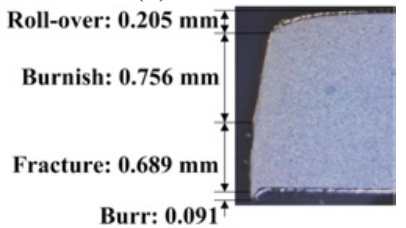

(d)

Figure 6. Verification of operation window shown in Fig. 4(b); (a) $C=0.1 \mathrm{~mm}$ with $E_{p}=0 \%$, (b) $C=0.2 \mathrm{~mm}$ with $\mathrm{E}_{\mathrm{p}}=0 \%$, (c) $\mathrm{C}=0.1 \mathrm{~mm}$ with $\mathrm{E}_{\mathrm{p}}=100 \%$ and (d) $\mathrm{C}=0.2 \mathrm{~mm}$ with $\mathrm{E}_{\mathrm{p}}=100 \%$ using $\mathrm{D}_{\mathrm{h}}=1.0 \mathrm{~mm}$.

Figures 6 and 7 shows experimental results for trimming of inclined part with $\theta=-10^{\circ}$ and $+10^{\circ}$ under $\mathrm{D}_{\mathrm{h}}=1.0 \mathrm{~mm}$. Effective mechanical trimming of inclined part can be performed with $\mathrm{C}=0.1 \mathrm{~mm}$ without regard to position error (Figs. 6(a), 6(c), Figs. 7(a), 7(c)). But, similar to the results of Fig. 5, position error in large clearance, such as $\mathrm{C}=0.2$ and $\mathrm{C}=0.3 \mathrm{~mm}$, resulted in relatively large height of burr (Figs. 6(b), 6(d), Figs. 7(b), 7(d)).

The operation windows obtained from FE-simulation were good agreement with the results of experiment. Taking into account that allowable burr height is normally $100 \mu \mathrm{m}$ in actual field, range of effective mechanical rimming can be more extended than that suggested in this study. This indicates mechanical trimming using hot half-trimming can be applied to hot stamping with strong robustness for process variables.

\section{Conclusions}

In this study, the effect of position error on the trimmed edge in mechanical trimming using hot half-trimming for flat and inclined part was investigated and then a suitable operation window was 


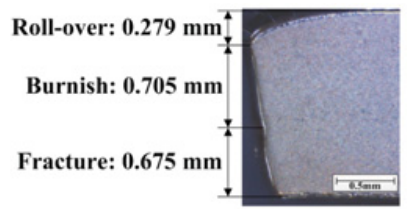

(a)

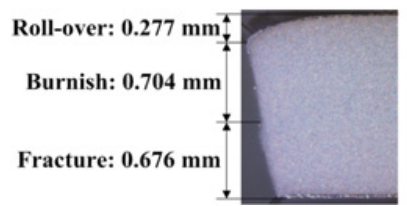

(c)

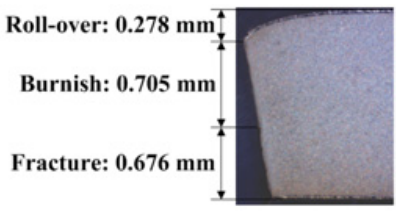

(b)

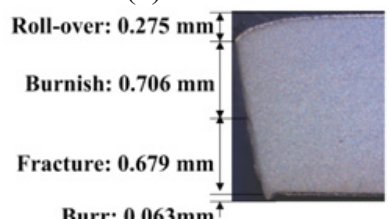

(d)

Figure 7. Verification of operation window shown in Fig. 4(c); (a) $\mathrm{C}=0.1 \mathrm{~mm}$ with $\mathrm{E}_{\mathrm{p}}=0 \%$, (b) $\mathrm{C}=0.2 \mathrm{~mm}$ with $\mathrm{E}_{\mathrm{p}}=0 \%$, (c) $\mathrm{C}=0.1 \mathrm{~mm}$ with $\mathrm{E}_{\mathrm{p}}=100 \%$ and (d) $\mathrm{C}=0.3 \mathrm{~mm}$ with $\mathrm{E}_{\mathrm{p}}=66 \%$ using $\mathrm{D}_{\mathrm{h}}=1.0 \mathrm{~mm}$.

constructed for the application of this process to real hot stamping. It was verified that mechanical trimming using hot half-trimming can be performed sucessfully for both flat and inclined part when position error did not exist during the transfer of hot half-trimmed part to mecahnical trimming press. It was finally determined from the operation window for given boron steel with thickness of $1.6 \mathrm{~mm}$ that effective mechanical trimming using hot half-trimming for both trimming of flat and inclined part was possible with $\mathrm{D}_{\mathrm{h}}=1.0 \mathrm{~mm}$ in hot half-trimming and clearance between $0.1 \mathrm{~mm}$ and $0.124 \mathrm{~mm}$ in subsequent mechanical trimming without regard to position error.

This research was financially supported by the Ministry of Trade, Industry and Energy(MOTIE) and Korea Institute for Advancement of Technology(KIAT) through the Promoting Regional specialized Industry, and by the National Research Foundation of Korea (NRF) grant funded by the Korea government (MSIP) (No. 2012R1A5A1048294)

\section{References}

[1] I. Picas, R. Hernandez, D. Casellas, B. Cases, I. Walls, Proc. of 1st CHS, 179 (2008)

[2] H. So, D. Faßmann, H. Hoffmann, R. Golle, M. Schaper, J. Mater. Proc. Technol. 212, 437 (2012)

[3] K. Mori, T. Maeno, Y. Maruo, CIRP Annals-Manuf. Technol. 61, 255 (2012)

[4] H.S. Choi, B.M. Kim, D.H. Kim, D.C. Ko, Int. J. Precis. Eng. Manuf. 15, 1087 (2014)

[5] H.S. Choi, B.M. Kim, D.C. Ko, J. Mech. Sci. Technol. 28, 2319 (2014) 